\title{
The Influences of Solar Activities on TEC Variations of Equatorial Ionosphere over Sri Lanka
}

\author{
R. Jenan ${ }^{1}$, T. L. Dammalage ${ }^{1}$, A. Kealy ${ }^{2}$ \\ ${ }^{1}$ Faculty of Geomatics, Sabaragamuwa University of Sri Lanka, Sri Lanka \\ ${ }^{2}$ School of Science, RMIT University, Victoria 3001, Australia \\ E mail (thilantha@geo.sab.ac.lk).
}

\section{Accepted: 21 January 2020}

\begin{abstract}
Solar activities produce significant influence on the ionospheric electron density variation, which results in unexpected signal propagation delays through ionosphere and ultimately degrade the GNSS performances. The implementation of six Continuously Operating Reference Station network (CORSnet) in Sri Lanka at the end of 2016 paved the way to access continuous GNSS data to investigate the behaviour of equatorial ionosphere over Sri Lanka for the first time. Therefore, this study aims to investigate the influence of solar activities on the equatorial ionospheric TEC over Sri Lanka including two common solar indices, Sunspot Number (SSN) and $10.7 \mathrm{~cm}$ solar radio flux (F10.7). In addition, the variation of TEC is also studied with respect to the diurnal, seasonal and latitudinal variations using data from CORSnet of Sri Lanka for a period of 12 months starting from October 2017. TEC were calibrated using Ciraolo methodology by applying carrier phase measurements of GPS and GLONASS systems. The correlation of Vertical TEC (VTEC) with F10.7 is moderate and weak with SSN. Though the diurnal variation shows same trend throughout the period, a high randomness could be observed during daytime around 11:00 to 14:00 (LT). Values of VTEC were higher during equinox months and lower during solstice period. A hint of fountain effect was observed where Kalutara $\left(6.58^{\circ} \mathrm{N}\right)$ showed higher TEC values and lower values were observed at Kegalle $\left(7.25^{\circ} \mathrm{N}\right)$, which is located more towards the magnetic equator.
\end{abstract}

\section{2019 BBSCS RN SWS. All rights reserved}

Keywords: GNSS, Solar Activity, lonosphere, TEC, CORS network

\section{Introduction}

Modern society depends on technologies that can be vulnerable to space weather, the phenomena which is mainly driven by the changes in the Sun. This makes dynamic variations in the space environment prevailing between the Sun and the Earth. The Sun follows an approximate 11-year cyclic activity depending on the number of sunspots on the solar surface (Lang 2001; Horozovic, Natras and Tabakovic 2018; Tian, Samanta and Zhang 2018). During a solar maximum, the Sun has higher number of sunspots with an increase in the intensity of solar emissions, occurrence of destructive coronal mass ejections (CMEs) and solar flares. These activities induce significant effects on the Earth, Earth's upper atmosphere, magnetosphere and satellite environment which make scientists, meteorologists and physicists pay significant attention to studying the space weather and Earth's upper atmosphere (Ya'acob, Abdullah and Ismail 2010).

The solar radiation from the Sun ionizes the air molecules and atoms producing free electrons and ions in the upper atmospheric region between $60 \mathrm{~km}$ to $1100 \mathrm{~km}$ known as the ionosphere (Başçiftçi et al. 2018). The Global Navigation Satellite System (GNSS) signals travelling 20,000 km through the space are subject to an amount of delay by the existing electrons in the ionosphere. These electrons along with the dispersive nature of the ionosphere enables unambiguous determination of the basic ionospheric parameter, the TEC (Bust and Mitchell 2008; Abdullah, Strangeways and Walsh 2009). Because of the worldwide and uninterrupted coverage provided by GNSS satellites, the TEC observations have become a powerful and valuable tool to investigate the state and structural variations of the ionosphere. Moreover, the ionosphere also shows significant amount of variations with seasons, latitude and longitude of earth depending on the solar conditions (Kamide and Chian 2007; Mansoori et al. 2016). In order to study the ionospheric variations with respect to these earth-related factors, scientists have divided the ionosphere into three major regions besides the layers separated by the altitude. Accordingly, polar, mid-latitude and equatorial regions of the ionosphere are shown in Fig. 1 (Başçiftçi et al. 2018). The polar ionospheric region also known as high latitude region, is located above and below the magnetic latitudes $60^{\circ}$ and $-60^{\circ}$, respectively. The mid latitude ionospheric region is located within $20^{\circ}$ to $55^{\circ}$.

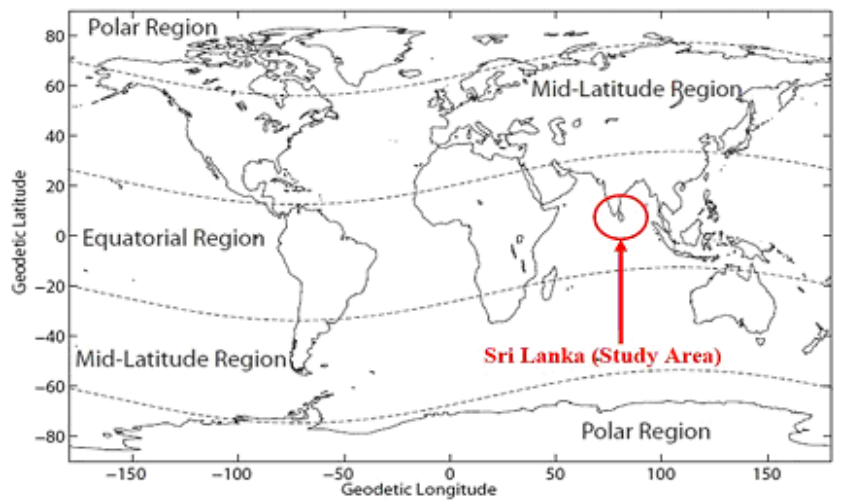

Figure 1: Division of earth into geomagnetic regions with study area (Memarzadeh 2009).

The equatorial ionospheric region is bounded within $20^{\circ}$ and $-20^{0}$ latitudes from geomagnetic equator. Scientists pay much attention to this ionospheric region due to it's unique features such as Equatorial Ionization Anomaly (EIA), Equatorial Electro Jet (EEJ), Equatorial Plasma Bubbles (EPB), fountain effect etc. (Reddy 1986; Komjathy 1997). In addition, the region shows highest value of peak electron density. The magnetic field lines run horizontally over magnetic equator enabling the electric fields to dominate the morphology of equatorial ionospheric region. These electric fields drive a strong EEJ in the E-region and the fountain effect in the F-region of equatorial ionosphere (Richmond 1973; Cervera and Thomas 2006; Ruilong et al. 2016). In addition to these effects, solar activity also produces significant disturbance to the electrodynamics of the equatorial ionospheric region (Liu et al. 2007; Kumar and Singh 2011; Ruilong et al. 2017).

Many researches (Rama Rao et al. 2006; Bhuyan and Borah 2007; Bagiya et al. 2009; Kumar and Singh 2011; Kumar et al. 2012) during last several decades have studied the morphological characteristics and solar activity influence on the equatorial ionosphere over Indian region, existing at the northern part of the 
geomagnetic equator using total electron content (TEC) measurements during varying solar active periods. However, the characteristics of the ionosphere in the southern part of the geomagnetic equator lying over Sri Lankan region is still unrevealed. At the end of three decades of long internal civil war (Dammalage, De Silva and Satirapod 2017), the national surveying and mapping agency of Sri Lanka has implemented Sri Lankan Continuously Operating Reference Station network (SLCORSnet) considering the promising requirement for Surveying, Engineering and Geographic Information System (GIS) applications within the country. Though the scope of SL-CORSnet was to assist the country's infrastructure development, the authors have tried to derive science out of it.

This study, for the first time investigates the solar activity influence on equatorial ionosphere over the Sri Lankan region based on GNSS derived TEC and study it's diurnal, seasonal and latitudinal variations. Understanding the behaviour of ionosphere over Sri Lankan region and modelling it for predictions would probably help to reduce the ionospheric induced error on GNSS positioning within the country.

\section{DATA AND METHODOLOGY}

\subsection{Data}

In order to calculate the TEC of the study area, dual frequency GNSS observation data from the SL-CORSnet were collected. The SL-CORSnet stations are located in Colombo, Kalutara, Rathnapura, Awisawella and Kegalla as shown in Fig. 2. The analysis presented in this paper is based on RINEX data obtained for the period of 12 months from 2017 to 2018, during solar cycle 24. In addition, the sunspot numbers were obtained from Solar Influences Data Analysis Centre (SIDC), of Royal Observatory of Belgium which is available at http://www.sidc.be/silso/datafiles\#total. Further, the solar index $10.7 \mathrm{~cm}$ solar radio flux was obtained from Canada, Department of Natural Resources and available through http://www.spaceweather.gc.ca/solarflux/sx-5-en.php.

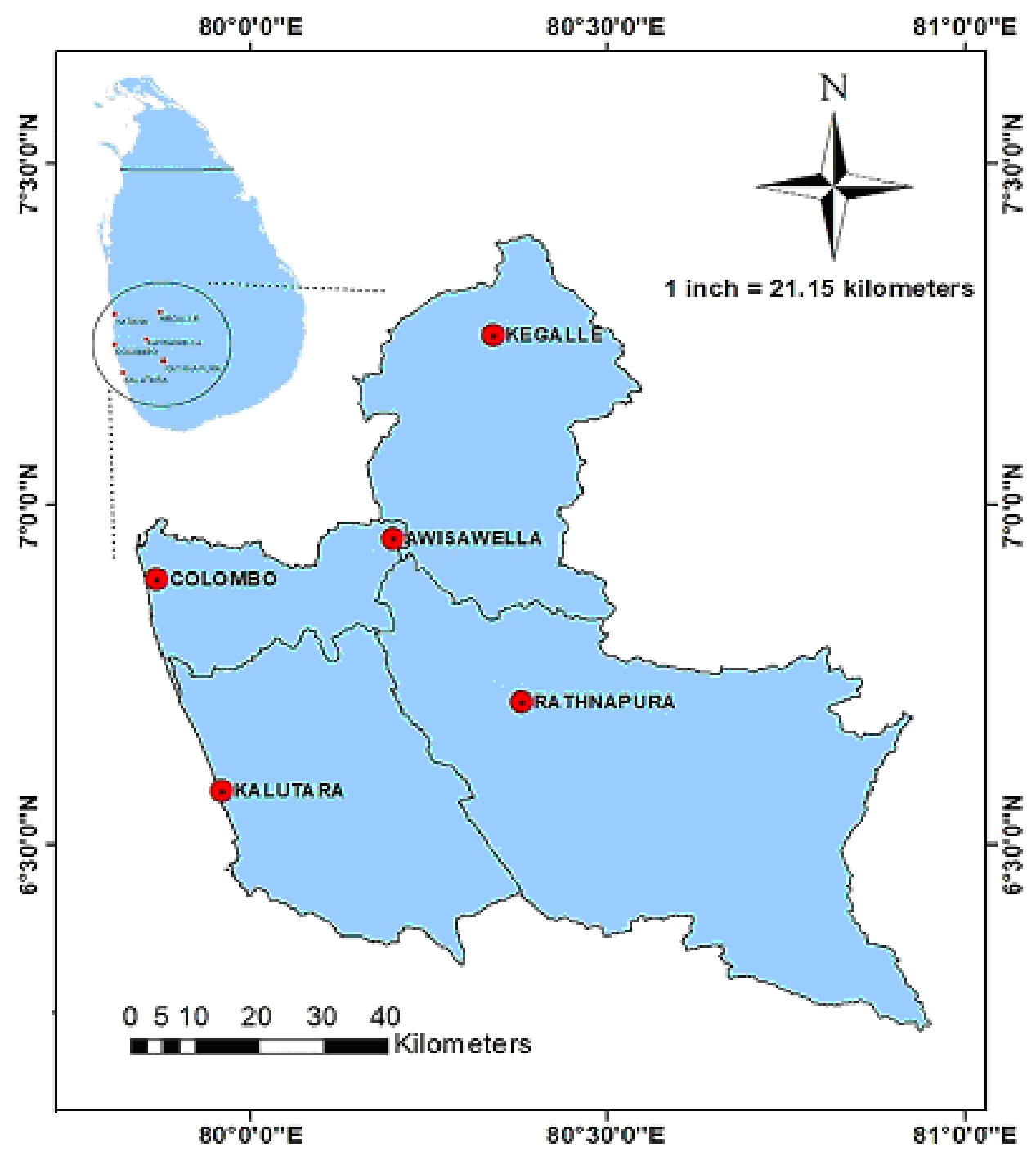

Figure 2 Location of SL-CORSnet stations along with the geomagnetic equator (black line in overview map of Sri Lanka).

\subsection{Methodology}

Carrier phase GNSS observation of GPS and GLONASS recorded at SL-CORSnet stations were utilized in slant TEC (STEC) calculation. The STEC values were estimated for all visible satellites, applying elevation mask of $50^{\circ}$. As a common practice, the ionosphere is approximated for a Single Layer Model
(SLM) and the height of the single ionospheric layer is selected between $350 \mathrm{~km}$ to $400 \mathrm{~km}$ in most of the previous experiments (Schaer 1999). In this study the height of the layer was selected to be $350 \mathrm{~km}$, where it is slightly above the expected level of highest electron density, as utilized by a study (Rama Rao et al. 2006) done within the Indian region. STEC values are estimated by 
using a combination of dual frequency observations as given in the equation 1.

$$
\Delta t=\frac{40.3 \times T E C}{c .\left(\frac{1}{f_{1}^{2}}-\frac{1}{f_{2}^{2}}\right)}
$$

Here $\Delta t$ is the differential time delay experienced on $L_{1}$ and $L_{2}$ frequencies. The mapping technique which depends on elevation was introduced to map the STEC into vertical TEC (VTEC) for the modelling of TEC. Equation 2 is used to derive VTEC out of the estimated STEC based on SL-CORSnet GNSS observations.

$$
F(z)=\frac{S T E C}{V T E C}
$$

Calibration of VTEC was performed by Ciaralo methodology (Ciraolo et al. 2007), using the program GNSS_VShell. Correlation coefficient (R) between VTEC and solar indices (F10.7 of SSN) was calculated as.

$$
R=\frac{\sum_{i=1}^{n}\left(x_{i}-\bar{x}\right) \cdot\left(y_{i}-\bar{y}\right)}{\sqrt{\sum_{i=1}^{n}\left(x_{i}-\bar{x}\right)^{2} \cdot \sum_{i=1}^{n}\left(y_{i}-\bar{y}\right)^{2}}}
$$

where $x_{\mathrm{i}}$ is VTEC value and $y_{\mathrm{i}}$ is solar index value (F10.7 or SSN) for a specific day. $\bar{x}$ and $\bar{y}$ represent the average value of VTEC and solar indices, respectively for the study period.

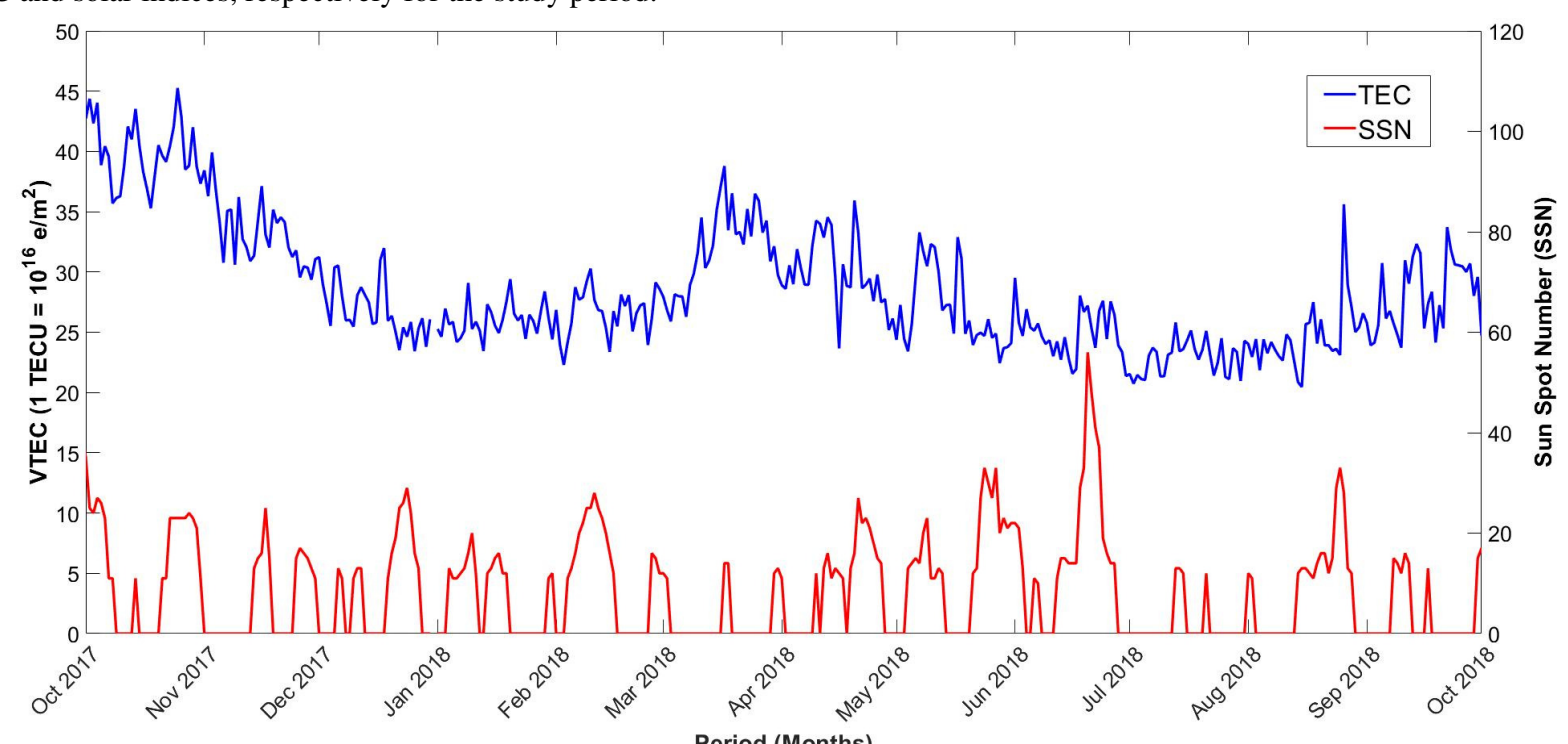

Period (Months)

Figure 3: Variation of maximum VTEC and SSN during the study period of 12 months.

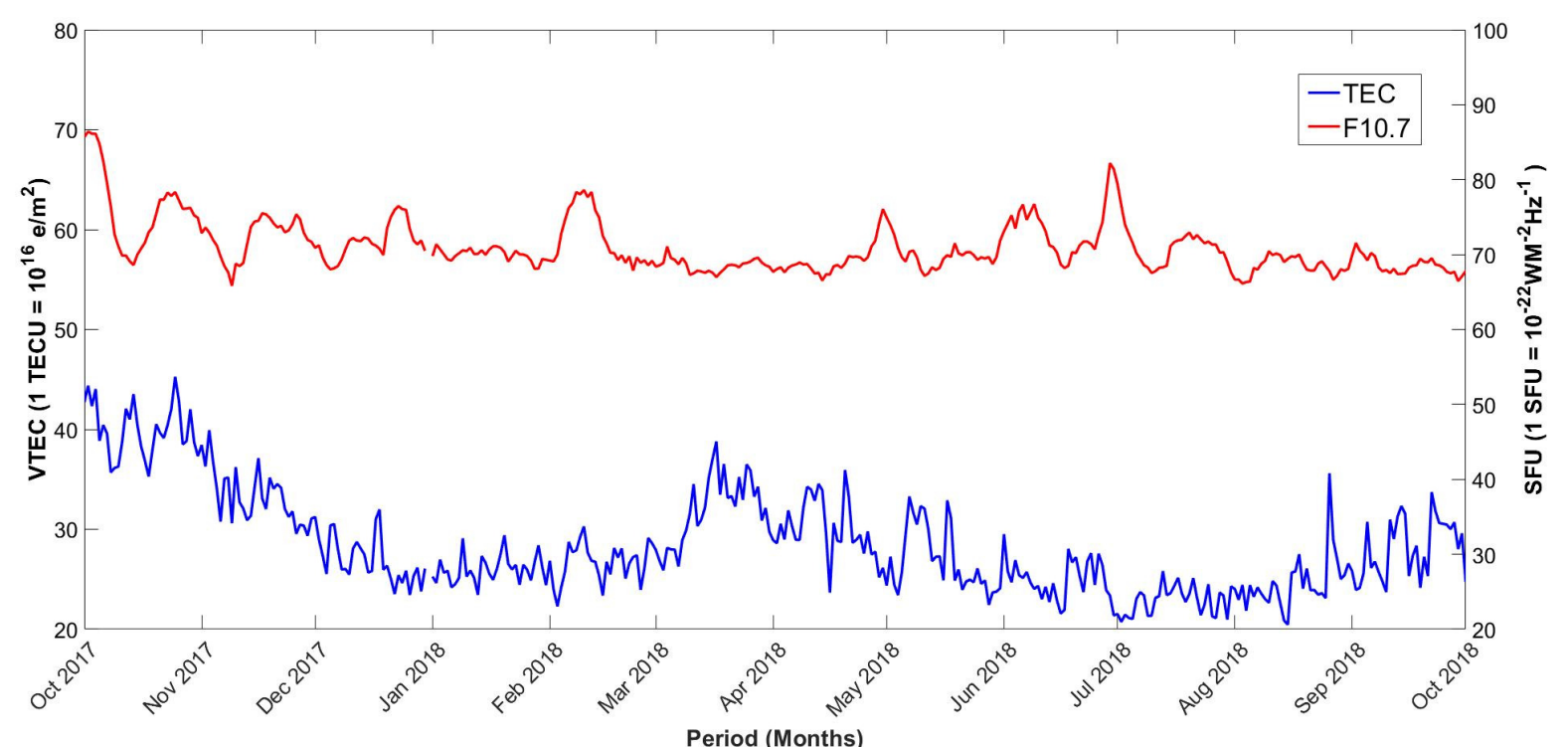

Figure 4: Variation of maximum VTEC and F10.7 during the study period of 12 months.

\section{RESULTS AND ANALYSIS}

\subsection{TEC Variation with Solar Activity}

We analyzed the variation of VTEC with solar activities by introducing the popular solar indices such as SSN and F10.7. Figures 3 and 4 illustrate the variability of daily maximum VTEC values, independent of the time of the day as shown in blue lines for the period from October 2017 to October 2018. Daily maximum VTEC values were comparatively high during the autumn month of October in 2017. It was followed by a VTEC decline throughout the winter season during December 2017 to February 2018 until the next peak, noticed in spring months of March to May of 2018. A cyclic variation of VTEC is noticeable where the lowest VTEC within the study period was recorded during July 2018. Moreover, the comparative variation of VTEC confirmed the identification of 2018 as a year with higher spotless days $(61 \%)$ on the Sun compared to 2017.

Generally solar radiations are measured in terms of three solar indices, i.e. EUV flux, F10.7, and SSN. Out of these indices, F10.7 and SSN are commonly used in the absence of EUV flux data. The red lines in Figs. 3 and 4 show the variation SSN and F10.7, respectively. Both the solar indices show enhanced values, where only a few sudden variations have been observed during the study period. 


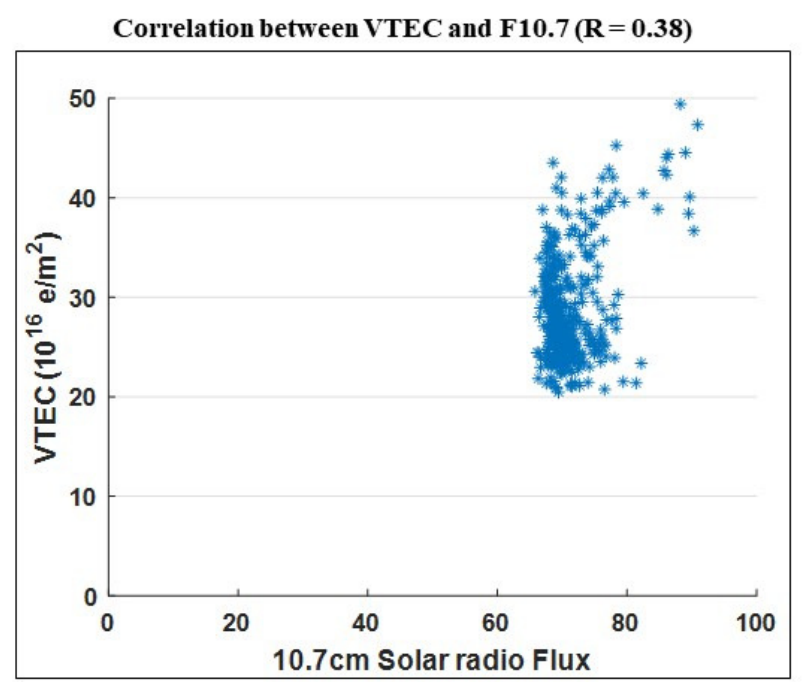

a)

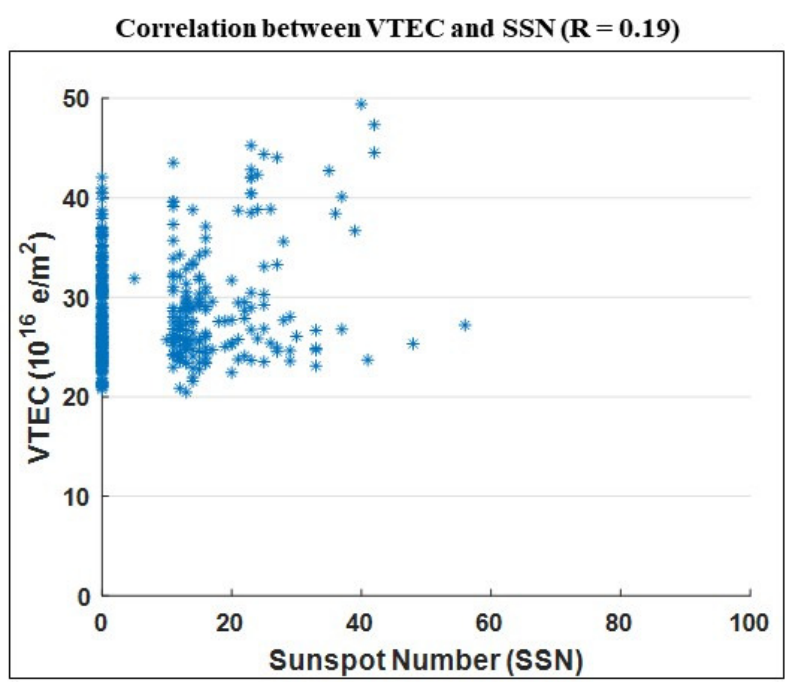

b)

Figure 5: Correlation between daily maximum TEC and daily mean solar indices: a) SSN, b) F10.7.

Comparing Figs. 3 and 4, we see that the solar indices, SSN and F10.7 do not have a high correlation with the VTEC during the period of solar minimum. In order to analyze the relationship between the solar activities and VTEC variations over Sri Lanka, the correlation coefficients were calculated. Figure 5 a) and b) show the correlation between the solar indices and VTEC during this study period. F10.7, shows a moderate level of relationship ( $\mathrm{R}$ $=0.38$ ) with the VTEC which is comparatively higher than the SSN, which shows a weak relationship $(\mathrm{R}=0.19)$ with the VTEC.

\subsection{Diurnal TEC Variation}

In order to understand the diurnal variation of ionospheric TEC over Sri Lankan region mass plots of VTEC of each month within the study period have been studied. Figure 6 shows the diurnal variation of VTEC during the month of November 2017, as an example. Accordingly, a short-lived pre-dawn minimum TEC is shown between 05:00 to 06:00 LT, in the early morning, at every station while the maximum TEC value occurs between 13:00 to 15:00 LT in the afternoon. Diurnal variation in TEC maintains a minimum value throughout the night period and shows a steady increase with the sunrise and reaches the maximum TEC value during early afternoon, which then falls gradually after sunset. The peak diurnal TEC values vary between 25 - 40 TEC units (TECU) everyday where the minimum TEC values vary between 3 - 15 TECU at each station.

One of the significant features that is noticeable in the figure 6 is the randomness in the variation of TEC of each day, particularly during early and late afternoon periods, but the nighttime TEC variations are almost constant. This randomness in TEC variation may be due to changes in the activities of the Sun and its associated changes, in the intensity of incoming radiations and the zenith angle at which they interact with the upper atmosphere of the earth. In addition, these daily variabilities can be significantly influenced by the EEJ strength and plasma flow associated with the EIA in the observed TEC in the different stations in the Sri Lankan region. Although, similar patterns of variations in TEC as shown in the figure 6 were observed for all the months of different seasons during the period of analysis, where time of peak TEC occurrence and peak TEC values varied with seasons and latitude of the stations. Though this preliminary results on the diurnal variation of TEC is interesting, a complete understanding of the diurnal variability of the Sri Lankan ionosphere could not be achieved due to the limited number of CORS stations within the Sri Lankan region.

\subsection{Seasonal Variation in TEC}

Seasonal variation of ionospheric TEC over the Sri Lankan region during the study period has also been analysed by plotting the seasonal median VTEC variation of each station. Figure 7 shows the variation of VTEC during the period of equinox, summer and winter months of the Avissawella $\left(6.95^{\circ} \mathrm{N}\right)$ station. The seasonal period of equinox has been selected as a combination of March, April September and October while May, June, July of 2017 and August of 2018, represent the summer solstice. Winter solstice has been represented by November, December of the year 2017 and January, February of the year 2018.

It is clearly seen from the figure 7 that the diurnal peak VTEC value is higher (28.5 TECU) during the equinox period and lower (22 TECU) during the summer period. The occurrence of diurnal peak VTEC value is around 13:00 to 14:00 LT during summer and winter periods where it is slightly delayed around 16:00 LT during the equinox months. Equinox and winter periods show a gradual fall of TEC after sunset where large variation is observable during summer period which is maintained throughout the night-time. Similar patterns of seasonal variations in TEC were noticed during the study period at all the five stations.

The same trend of TEC variations have been noticed during quiet ionospheric periods over Indian region by where the amplitude of maximum VTEC was higher during equinox period continued by winter and lower during summer (Bhuyan and Borah 2007; Mukherjee et al. 2010). These studies suggest that these variations are due to the variation of observed solar flux over the period of observation and due to semi-annual changes in the neutral composition driven by the more mixed atmosphere due to winter downwelling and summer upwelling. Furthermore, TEC during winter is higher (25 TECU) compared to the VTEC in summer exhibiting the winter anomaly caused by the seasonal changes in neutral gas composition. This is primarily caused with the downward vertical winds in winter resulting in increment of $\mathrm{O} / \mathrm{N}_{2}$ ratio and low ionization rates. Along with these results, and evident from figure 3 and 4, showing cyclic variation of VTEC over this region, it is clear that the equatorial ionosphere over Sri Lanka shows a seasonal dependency in TEC variation. 

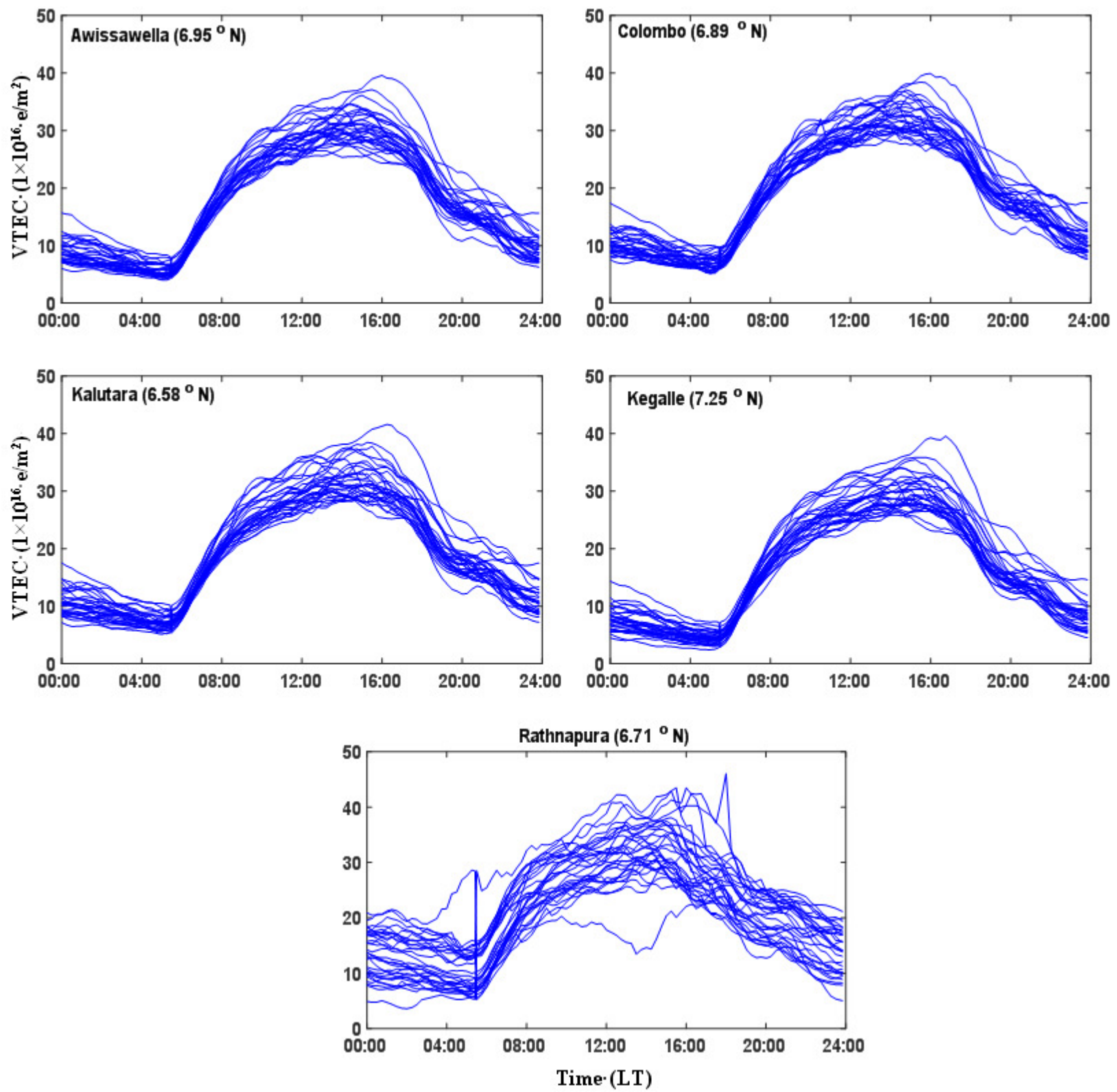

Figure 6: Mass diurnal curves of VTEC at five stations, during the month of November 2017

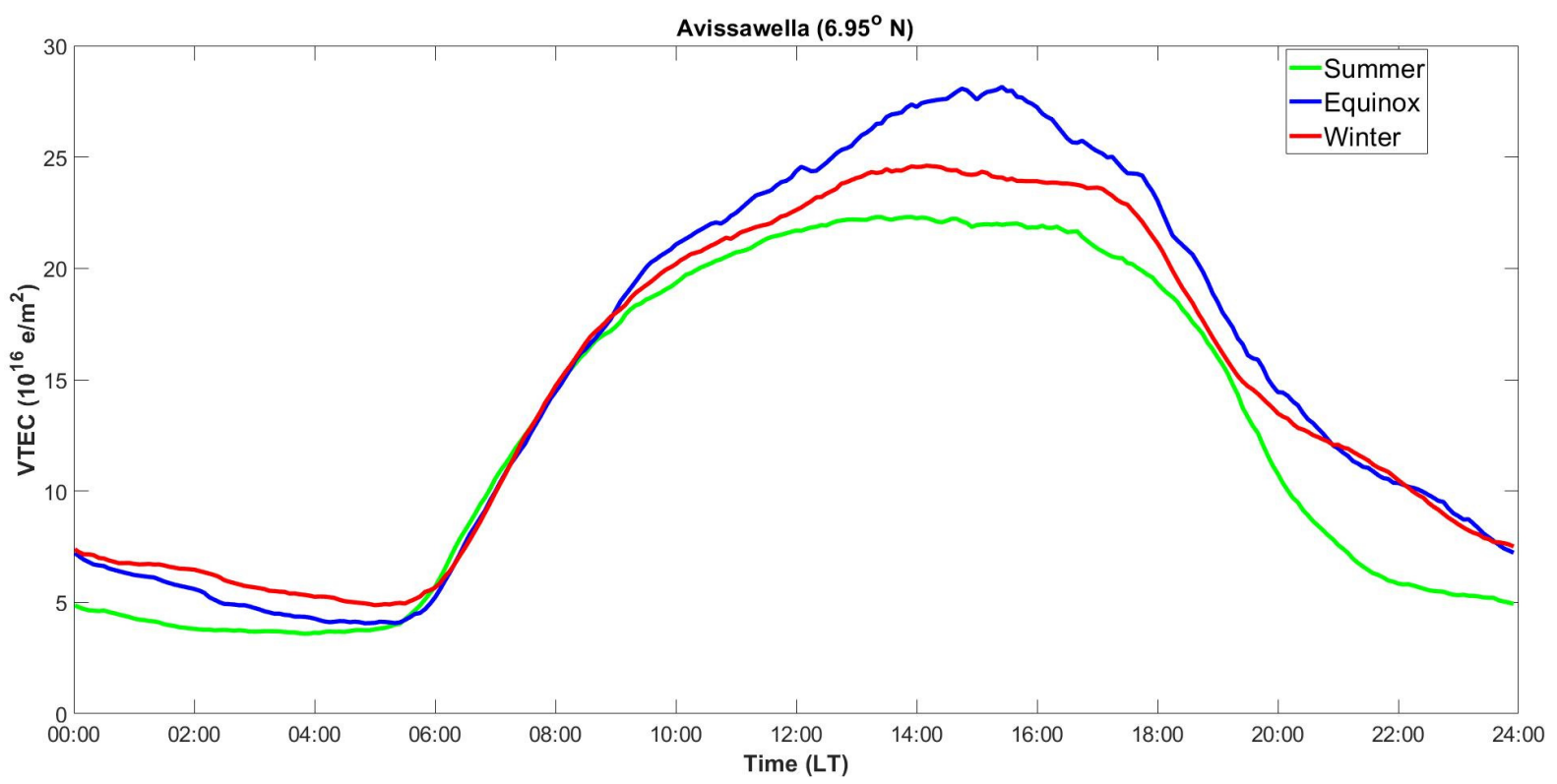

Figure 7: Seasonal TEC variation at Avissawella station. 


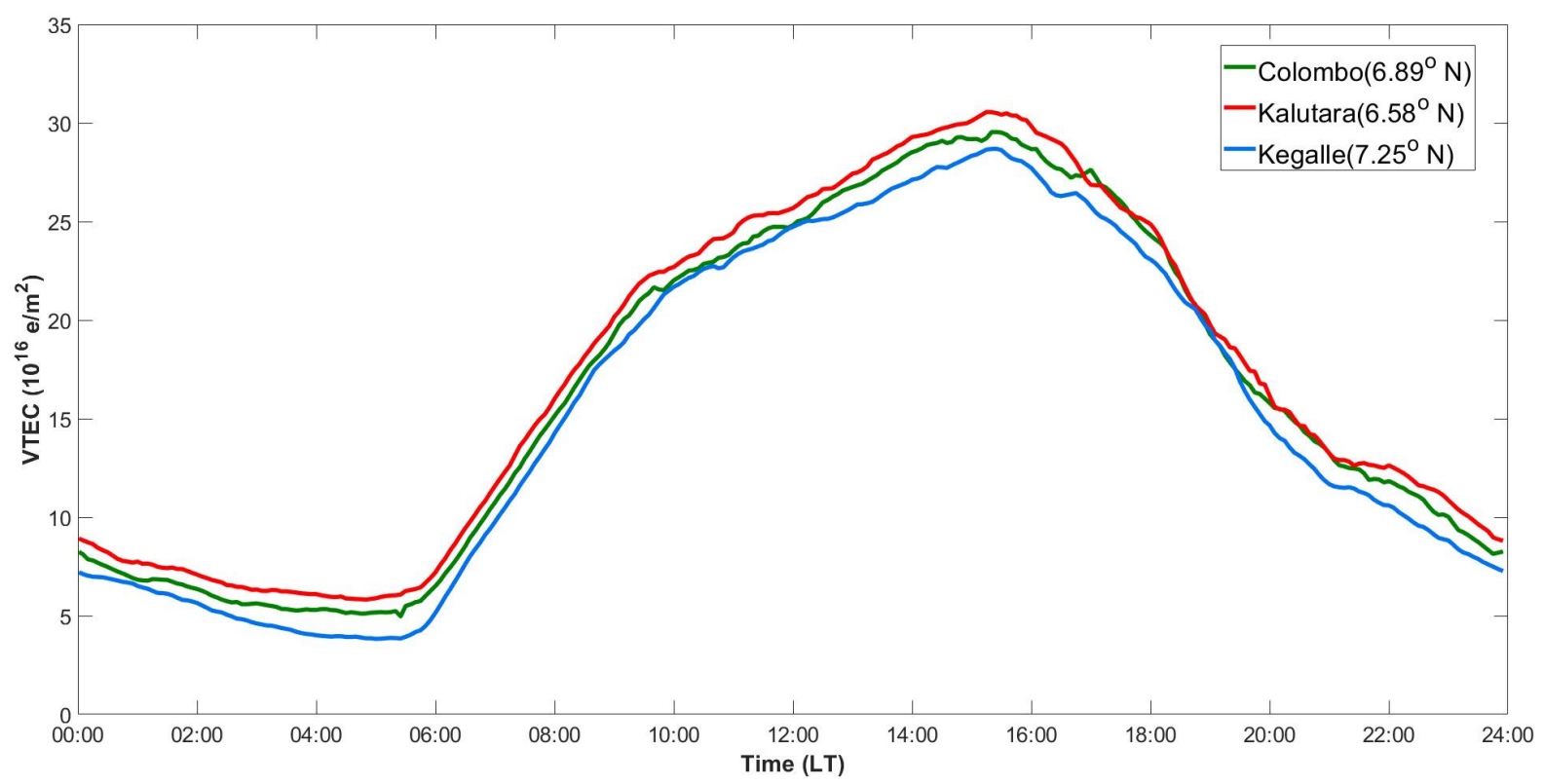

Figure 8: Latitudinal variation in VTEC at each of the stations during equinox months.

\subsection{Latitudinal Variation in TEC}

Geographical location of Sri Lanka is very unique to study the latitudinal variations of equatorial ionosphere as the geomagnetic equator passes over the upside tip of the country through the Indian region. In order to study the variations in TEC as a function of latitude over the Sri Lankan region, VTEC data derived from the stations Kalutara $\left(6.58^{0} \mathrm{~N}\right)$, Colombo $\left(6.89^{\circ} \mathrm{N}\right)$ and Kegalle $\left(7.25^{\circ} \mathrm{N}\right)$, which are located along a common meridian of $80^{\circ} \mathrm{E}$ have been considered to eliminate the longitudinal variation effects on VTEC.

Variations in VTEC over these stations during equinox, winter and summer seasons during the study period were analysed. Accordingly, the latitudinal VTEC variations at the said stations during the equinox period is shown in Fig. 8. The maximum peak TEC value of 31 TECU occurs around 16:00 LT over Kalutara station and the lowest peak TEC value of 28 TECU over Kegalle station during same period. Higher TEC value is observed over the Kalutara station, followed by Colombo and Kegalle during most of the period throughout the day. This result is a clearly due to the fountain effect, which is the most prominent feature in the equatorial ionospheric region. The phenomenon of fountain effect increases the ionization in both sides of the magnetic equator which increases the TEC distributions over the stations that are located away from the magnetic equator (Kalutara) and the stations nearer to the magnetic equator (Kegalle) has the lower TEC distribution. The latitudinal variation analysis shows almost a similar pattern during other seasons as well.

A significant deviation of latitudinal TEC variation was not observed among the considered stations as the geographical location of the existing SL-CORSnet stations were not widely spread along the latitude. The obtained results are encouraging enough to further investigate the latitudinal TEC variation over Sri Lankan region using the proposed expansion of SL-CORSnet to be implemented in the near future.

\section{CONCLUSIONS}

Many studies have been carried out to understand the morphology of the equatorial ionosphere during last couple of decades. However, this study aims to analyse the influence of solar activity on the equatorial ionosphere over Sri Lanka and to study the diurnal, seasonal, and latitudinal variation of the ionospheric TEC. The vertical TEC derived from five Continuously Observing Reference Stations within Sri Lanka has been used for this analysis. The equatorial ionosphere over Sri
Lanka shows cyclic variation throughout the study period. Solar activity shows a moderate level of influence on the ionosphere over this region. F10.7 shows a better correlation of 0.38 with VTEC than SSN, which shows a weak correlation of 0.19. Diurnal TEC variation shows high randomness during the noon time and the ionospheric TEC variation has been quiet during night and can be attributed to the absence of solar radiation at nighttime. Further, this also depends on the intensity of the incoming rays and zenith angle variation. Ionospheric TEC over Sri Lanka shows seasonal variations as a result of changes in neutral gas composition where the TEC values have been high during equinox months followed by winter solstice and summer months. Latitudinal TEC variations depict the existence of the fountain effect well below the geomagnetic equator, which has enhanced the TEC values over the stations near the geomagnetic equator. This study reveals certain aspects of the characteristics of equatorial ionosphere over Sri Lanka. However, it is important to carry out this analysis covering a longer period of time during varying solar active conditions to investigate further into the TEC variation in this specific ionospheric region. Further analysis is also needed on the latitudinal variations of TEC inducing stations, that are well distributed along the latitude within Sri Lanka.

\section{Acknowledgements}

Authors would like to thank Geodetic unit of the Survey Department of Sri Lanka for providing the GNSS observations of SL-CORSnet for this study, Dr. Luigi Ciraolo for providing the program GNSS_Vshell for the TEC estimations and for all the other institutes for providing online data that were required for the study. RJ thanks the International Space Weather Initiative (ISWI) for providing financial support to attend the ICTP/ISWI workshop where these results were presented. 


\section{References}

Abdullah, M., Strangeways, H. and Walsh, D. M. A.: 2009. Journal of Navigation, 62, 151-166, doi: $10.1017 /$ S0373463308004979.

Bagiya, M., Joshi, H., Iyer, K., Aggarwal, M., Ravindran, S. and Pathan, a.: 2009. Annales Geophysicae, 27, doi: 10.5194/angeo-27-1047-2009.

Başçiftçi, F., Inal, C., Yildirim, O. and Bülbül, S.: 2018. International Journal of Engineering and Geosciences, 3, doi: $10.26833 /$ ijeg. 382604.

Bhuyan, P. and Borah, R. R.: 2007. Advances in Space Research, 39, 830-840, doi: $10.1016 /$ j.asr.2006.12.042.

Bust, G. and Mitchell, C.: 2008. Reviews of Geophysics, 46, doi: 10.1029/2006RG000212.

Cervera, M. and Thomas, R. M.: 2006. Annales Geophysicae, 24, doi: 10.5194/angeo-24-3329-2006.

Ciraolo, L., Azpilicueta, F., Brunini, C., Meza, A. and Radicella, S.: 2007, Calibration Errors on Experimental Slant Total Electron Content (TEC) Determined with GPS, 111-120.

Dammalage, T., De Silva, D. N. and Satirapod, C.: 2017, Performance analysis of GPS Aided geo augmented navigation (GAGAN) over Sri Lanka, 305-314.

Horozovic, D., Natras, R. and Tabakovic, A.: 2018, Proceeding of the First Western Balkan Conference on GIS, Albania, Chapter: 2, pp.238-246

Kamide, Y. and Chian, A.: 2007, Handbook of the Solar-Terrestrial Environment, Springer: 28 - 150, doi: 10.1007/978-3-54046315-3_8.

Komjathy, A.: 1997, PhD Thesis, Department of Geodesy and Geomatics Engineering, University of New Brunswick. 265.

Kumar, D. S., Priyadarshi, S., Seemala, G. and Singh, A.: 2012. Astrophysics and Space Science, 339, 165-178, doi: 10.1007/s10509-011-0973-6.

Kumar, S. and Singh, A. K.: 2011. Advances in Space Research, 47, 4, 710-717, doi: 10.1016/j.asr.2010.10.015.

Liu, H., Lühr, H., Watanabe, S., Köhler, W. and Manoj, C.: 2007. Journal of Geophysical Research, 112, doi: 10.1029/2007JA012313.

Mansoori, A., Khan, P., Ahmad, R., Atulkar, R., Aslam, A., Bhardwaj, S., Malvi, B., Purohit, P. and Gwal, A.: 2016. Journal of Physics Conference Series, 759, doi: 10.1088/1742-6596/759/1/012069.

Memarzadeh, Y.: 2009, PhD Thesis, Delft University of Technology. 243.

Mukherjee, S., Sarkar, S., Purohit, P. and Gwal, A.: 2010. Advances in Space Research, 46, 291-295, doi: 10.1016/j.asr.2010.03.024.

Lang, K. R.: 2001, The Cambridge Encyclopedia of the Sun, Cambridge University Press, Cambridge, 268.

Reddy, C. A.: 1986. Indian Journal of Radio and Space Physics, 15, 247-263.

Richmond, A.: 1973. Journal of Atmospheric and Terrestrial physics, $35,6,1083-1103$.

Ruilong, Z., Liu, L., Le, H. and Chen, Y.: 2016. Journal of Geophysical Research: Space Physics, 121, doi: 10.1002/2016JA022491.

Ruilong, Z., Liu, L., Le, H. and Chen, Y.: 2017. Geophysical Research Letters, doi: 10.1002/2017gl073238.

Schaer, S.: 1999, PhD Thesis, Bern University, Switzerland.

Tian, H., Samanta, T. and Zhang, J.: 2018. Geoscience Letters, 5, doi: 10.1186/s40562-018-0103-1.

Rama Rao, P. V. S., Niranjan, K., Prasad, D., Seemala, G. and Gouthu, U.: 2006. Annales Geophysicae, 24, doi: 10.5194/angeo-24-2159-2006.

Rama Rao, P. V. S., Seemala, G., Niranjan, K. and Prasad, D.: 2006. Annales Geophysicae, 24, doi: 10.5194/angeo-243279-2006.

Ya'acob, N., Abdullah, M. and Ismail, M.: 2010, GPS Total Electron Content (TEC) Prediction at Ionosphere Layer over the Equatorial Region, doi: 10.5772/8474. 